$\begin{array}{lllllll}\text { C } & & \text { A } & & & & \text { E } \\ \text { R } & \text { E } & \text { P } & \text { O } & \text { R } & \text { T }\end{array}$

\section{Aorto-oesophageal fistula and aortic pseudoaneurysm caused by a swallowed fish bone}

We describe a rare case of aorto-oesophageal fistula and aortic pseudoaneurysm in a middleaged man, who presented with chest pain and haematemesis 1 week after swallowing a fish bone. Oesophagogastroduodenoscopy and computed tomographic angiography findings were consistent with oesophageal perforation, proximal descending aortic pseudoaneurysm, and aorto-oesophageal fistula. Thoracic endovascular aortic repair was performed. The patient died from severe mediastinal sepsis. Early surgical intervention and broad-spectrum antibiotic therapy are crucial in preventing life-threatening mediastinal infection.

\section{Introduction}

Swallowed fish bones commonly impact in the upper digestive tract, mainly in the pharynx and oesophagus. Serious complications include deep neck abscess, mediastinitis, oesophageal perforation, extra-gastrointestinal migration of the fish bone, and vascular injury. We report a rare instance of aorto-oesophageal fistula with aortic pseudoaneurysm, caused by a swallowed fish bone.

\section{Case report}

A 54-year-old man presented with upper chest pain for a week after accidental swallowing a fish bone in January 2012. He had two bouts of haematemesis and worsening of odynophagia (painful swallowing) and dysphagia for which he was admitted, and developed fever on that day. Emergency oesophagogastroduodenoscopy was performed. A perforation and granulation tissue were noted at the thoracic oesophagus, $25 \mathrm{~cm}$ from upper incisors. There was profuse bleeding from the perforation site during the procedure.

Urgent computed tomographic angiography of thorax revealed a saccular outpouching which arose from the medial wall of the descending aorta the level of carina, denoting a pseudoaneurysm (Fig 1). There was no active contrast extravasation in arterial phase to suggest active bleeding. Adjacent peri-aortic fluid with multiple air pockets were identified, which suggested mediastinitis and pneumomediastinum. The thoracic oesophagus was externally compressed by the pseudoaneurysm.

The diagnosis was aorto-oesophageal fistula with proximal descending aortic pseudoaneurysm, complicated with mediastinitis secondary to fish bone impaction. The fish bone was probably dislodged and entered the distal gastro-intestinal tract, after
Key words Aneurysm, false; Esophageal fistula; Esophagus; Vascular fistula

Hong Kong Med J 2013;19:542-4 DOI : $10.12809 / \mathrm{hkmj} 133668$

Otorhinolaryngology Department Faculty of Medicine, University of Malaya, Malaysia

Surgery Department, Sibu Hospital, GD Ashok, MS Surgery DNB Radiology Department, Faculty of Medicine, University Malaysia Sarawak FMA Ahmad, MMed Radiology Department of Diagnostic Imaging, Sibu Hospital, Sarawak, Malaysia CKL Kong, MBBs

Correspondence to: Dr KJ Sia Email: kj_sia@yahoo.com KJ Sia, MBв Sarawak, Malaysia causing injury to the oesophagus.

The patient was transferred to a regional centre for further treatment, where he underwent an emergency thoracic endovascular aortic repair (TEVAR), with a Dacron stent graft. The size of the deployment system was $24 \mathrm{~F}$, roughly equal to a diameter of $8 \mathrm{~mm}$. The right external iliac artery diameter was assessed preoperatively to ensure the passage of the system. The stent graft was inserted via a right common femoral artery cut-down and deployed successfully across the neck of the pseudoaneurysm. After stent deployment, there was no further opacification of pseudoaneurysm following an aortogram (Fig 2) and bleeding from the aorto-oesophageal fistula stopped. The covered portion of the graft was placed just distal to the origin of left subclavian artery, and intravenous meropenem was started empirically. Staphylococcus aureus was isolated from blood culture. The patient was planned for a delayed oesophageal repair after stabilisation, but his clinical condition deteriorated and he died from fulminant mediastinal sepsis 1 week after the TEVAR.

\section{Discussion}

Impacted fish bone rarely causes serious complications. Nandi and Ong ${ }^{1}$ reported that among 2394 cases of foreign body ingestion, only $25(<1 \%)$ resulted in oesophageal 
perforation, two of which entailed an aortooesophageal fistula. Apart from aorta-oesophageal fistula, other rare cardiovascular complications include subclavian-oesophageal fistula, and pericardium perforation with cardiac tamponade.,.$^{2,3}$

Oesophageal perforation by fish bone allows introduction of pathogens into the mediastinum, which results in life-threatening mediastinitis. The wall of aorta is weakened and friable due to the surrounding inflammatory process and leads to later formation of an aortic pseudoaneurysm. The typical Chiari triad of an aorto-oesophageal fistula entails chest pain, initial sentinel haematemesis,

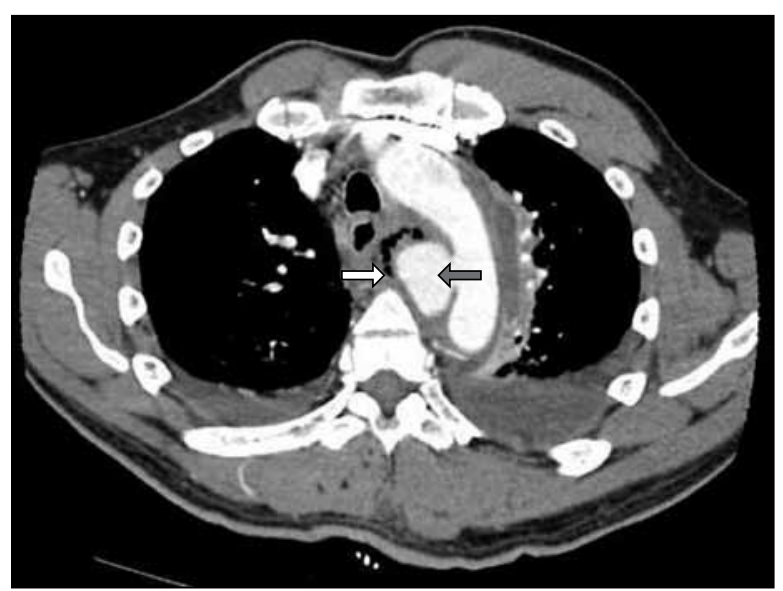

FIG I. An axial image of thoracic computed tomographic angiography shows a $3 \mathrm{~cm} \times 4 \mathrm{~cm} \times 4 \mathrm{~cm}$ focal saccular outpouching from the medial wall of proximal descending aorta at the level of carina (grey arrow). Peri-aortic mediastinal fluid and multiple air pockets are seen around this pseudoaneurysm (white arrow)

\section{因吞食魚骨而引致的主動脈食道廔管及主動脈 假性動脈瘤}

本文報告一宗主動脈食道廔管及主動脈假性動脈瘤的罕見病例。患者 為一名中年男性, 他誤吞魚骨後一星期出現胸部疼痛及嘔血。食管胃 十二指腸內窺鏡檢查和電腦斷層血管造影結果均顯示食道穿孔、近段 降主動脈假性動脈瘤和主動脈食道廔管。為病人進行胸主動脈腔內修 復, 但病人死於嚴重的縱隔敗血症。為病人盡早進行手術和使用廣譜 抗生素治療是防止危及生命的縱隔感染的關鍵。

and subsequent massive upper gastro-intestinal haemorrhage. Formation of thrombus in the fistulous tract can arrest the haemorrhage temporarily. ${ }^{4}$ However, the surrounding ongoing inflammation, friable granulation tissue, and high aortic pressure interfere with the healing process. Flexible oesophagoscopy may precipitate catastrophic haemorrhage by dislodging the unstable thrombus. ${ }^{5}$

Perforation of the oesophagus with aortic fistulation is usually fatal. ${ }^{6}$ Kelly et $\mathrm{al}^{7}$ reviewed over 100 documented cases of aorto-oesophageal fistula secondary to foreign body ingestion, and noted that only seven had survived 12 months. Conservative treatment of aorto-oesophageal fistula results in a $60 \%$ in-hospital mortality rate and zero late survival, whereas conventional surgical treatment is reported to have an in-hospital mortality of nearly $40 \%{ }^{8}$

Notably, TEVAR has gradually gained recognition as a technique for emergency treatment of aorto-oesophageal fistula, because it enables

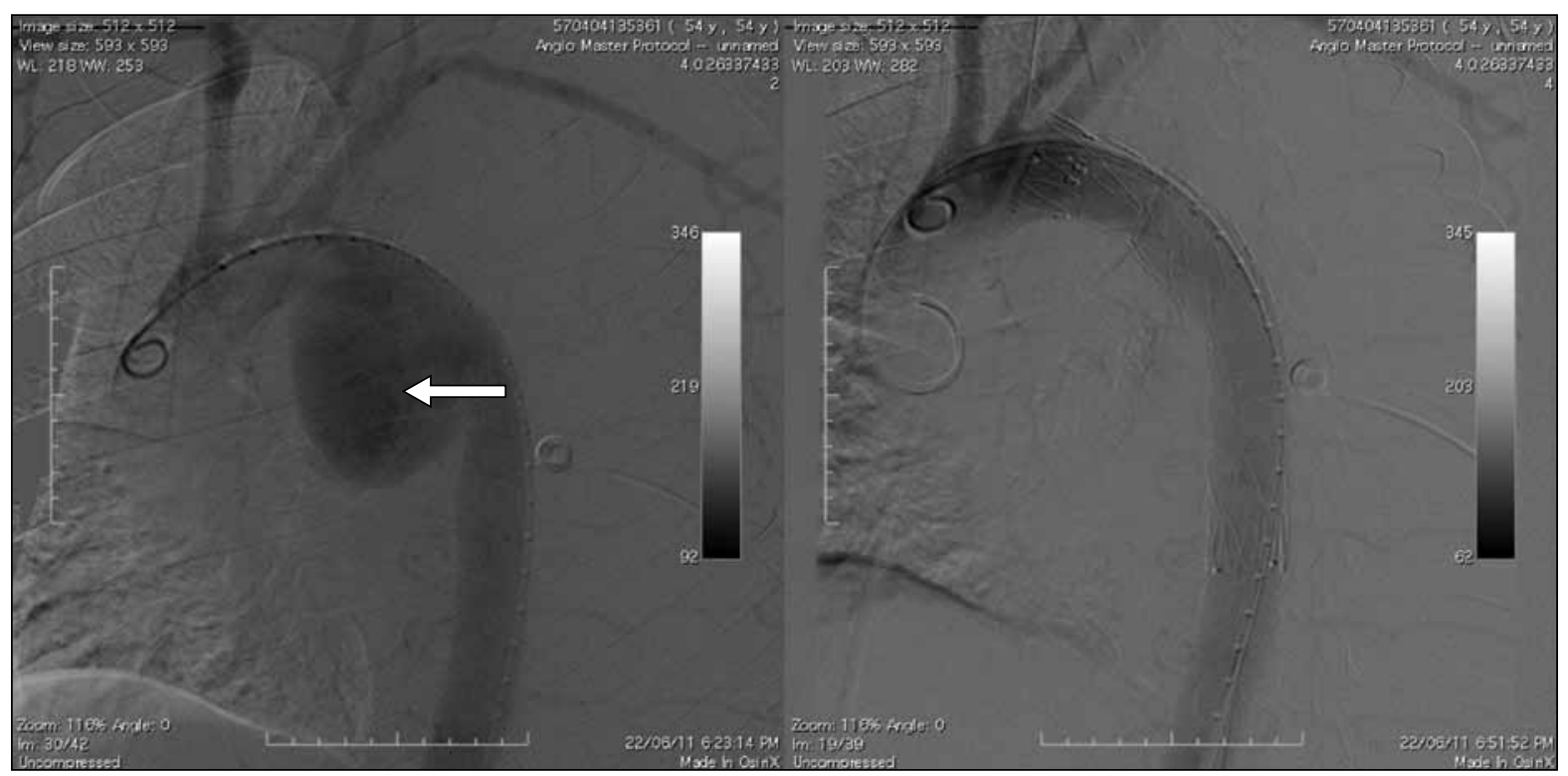

FIG 2. Flush aortogram pre- and post-endovascular aortic repair: the descending thoracic pseudoaneurysm neck is completely covered after deployment of the stent graft (arrow). There was no further opacification of pseudoaneurysm which indicates good early seal. The left subclavian artery remains patent 
rapid control of exsanguination through a lessinvasive approach than the conventional surgery. ${ }^{8}$ It provides valuable time to stabilise and optimise the patient's condition before proceeding to further interventions. Nevertheless, TEVAR alone leaves oesophageal perforation untreated, since it considerably increases the risk of mediastinitis and stent graft infection. In a retrospective case series by Jonker et al, ${ }^{9}$ early oesophageal repair after TEVAR was suggested to enable improved survival. Thus, TEVAR is considered a bridge to definitive surgery to deal with the immediate emergency. Whilst open oesophageal repair should be performed as soon as possible, ${ }^{9}$ thoracotomy, mediastinal debridement, and drainage with oesophagus reconstruction is a major procedure that confers a high risk of morbidity and mortality. Thoracoscopic mediastinal drainage and debridement has recently been described as an alternative. ${ }^{10}$ In this minimally invasive procedure, mediastinal disease is approached thoracoscopically, and a retrievable oesophageal stent is introduced to prevent spillage of saliva and oesophageal secretions through the fistula into the mediastinum. The oesophageal stent is removed at a later stage after the healing of the perforation. This combined technique involving minimally invasive procedures needs further evaluation of its feasibility and effectiveness.

Aorto-oesophageal fistula is very frequently associated with poor outcomes, and with or without surgical repair a high mortality should be anticipated. Broad-spectrum antibiotic therapy should be instituted early to minimise the effects of the mediastinitis that inevitably hampers survival. A gloomy prognosis was expected in this case because of the presence of mediastinitis when he presented to us.

Urgent computed tomographic angiography is essential to establishing the diagnosis and facilitate treatment planning of this rare entity. Early intervention and wide-spectrum antibiotic therapy are crucial before serious mediastinal infection supervenes, just as TEVAR is crucial to controlling exsanguination and haemodynamic stabilisation. Prompt open oesophageal repair is believed to improve survival. New combined minimally invasive thoracoscopic drainage and oesophageal stenting for the treatment of mediastinitis and oesophagus perforation still needs further evaluation as an alternative treatment. The survival rate remains low even with recent advances in surgery and endovascular aortic repair.

\section{References}

1. Nandi P, Ong GB. Foreign body in the oesophagus: review of 2394 cases. Br J Surg 1978;65:5-9. cross ref

2. Loh KS, Tan KK. Subclavian-oesophageal fistula as a complication of foreign body ingestion: a case report. Ann Acad Med Singapore 1998;27:277-8.

3. Sharland MG, MCCaughan BC. Perforation of the esophagus by a fish bone leading to cardiac tamponade. Ann Thorac Surg 1993;56:969-71. cross ref

4. Kunishige H, Myojin K, Ishibashi Y, Ishii K, Kawasaki M, Oka J. Perforation of the esophagus by a fish bone leading to an infected pseudoaneurysm of the thoracic aorta. Gen Thorac Cardiovasc Surg 2008; $56: 427-9$. cross ref

5. Benson MJ, Rouse D, van Someren N, Wingate DL, Swain CP. Fatal hemorrhage from an aorto-esophageal fistula precipitated by flexible endoscopy. Gastrointest Endosc 1991;37:193-6. cross ref

6. Scher RL, Tegtmeyer CJ, McClean WC. Vascular injury following foreign body perforation of the esophagus.
Review of the literature and report of a case. Ann Otol Rhinol Laryngol 1990;99:698-702.

7. Kelly SL, Peters P, Ogg MJ, Li A, Smithers BM. Successful management of an aorto-esophageal fistula caused by a fish bone - case report and review of literature. J Cardiothorac Surg 2009;4:21. cross ref

8. Marone EM, Coppi G, Kahlberg A, Tshomba Y, Chiesa R. Combined endovascular and surgical treatment of primary aorto-esophageal fistula. Tex Heart Inst J 2010;37:722-4.

9. Jonker FH, Heijmen R, Trimarchi S, Verhagen HJ, Moll $\mathrm{FL}$, Muhs BE. Acute management of aortobronchial and aortoesophageal fistulas using thoracic endovascular aortic repair. J Vasc Surg 2009;50:999-1004. cross ref

10. Chen X, Li J, Chen J, Zhou Y, et al. A combined minimally invasive approach for the treatment of aortoesophageal fistula caused by the ingestion of a chicken bone: case report and literature review. Clinics (Sao Paulo) 2012;67:195-7. cross ref 